\title{
Length-Weight Relationships, Maturity, and Reproductive Season of the Fringelip Mullet Crenimugil crenilabis (Forsskål, 1775) from the Arabian Sea Coast of Oman
}

\author{
Abdullah Al-Nahdi*1, Abdulaziz Al-Marzouqi' ${ }^{1}$, Said Al-Shajibi ${ }^{1}$ \\ and Ahmed Al-Hosni ${ }^{2}$ \\ ${ }^{1}$ Marine Science and Fisheries Centre, P.O. Box 227 \\ PC 100, Muscat, Sultanate of Oman \\ ${ }^{2}$ Ministry of Fisheries Wealth, P.O. Box 427 \\ PC 100, Muscat, Sultanate of Oman
}

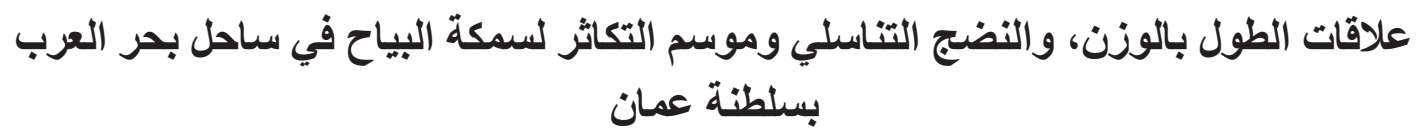

عبدالله النهدي، عبدالعزيز المرزوقي ، سعيد الشجيبي وأحمد الحوسني

الخلاصة: تم أخذت عينات سمكة البياح (Crenimugil crenilabis) في منطقتي الدقم وصلاله على بحر العرب شهريأ خلال

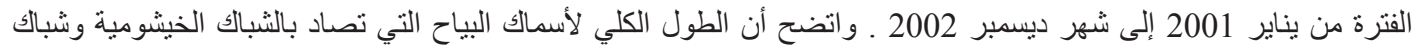

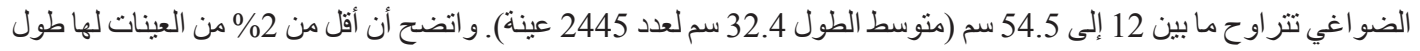

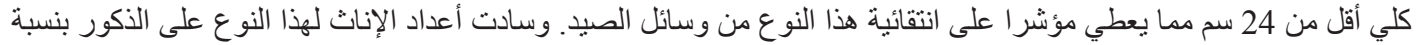

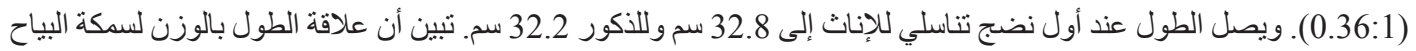

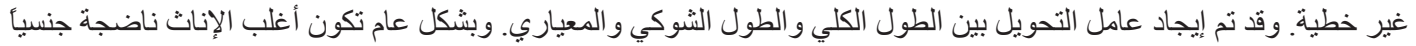

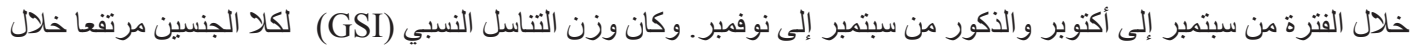

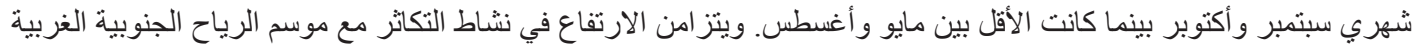

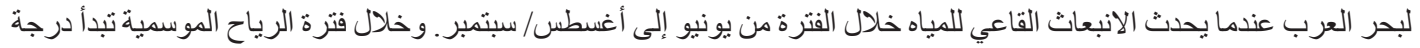

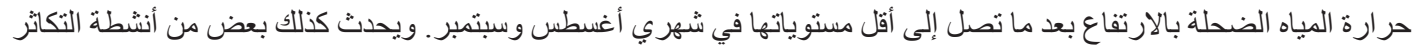

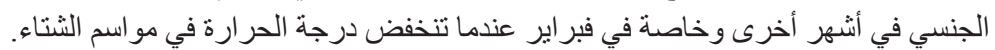

ABSTRACT: Fringelip mullet (Crenimugil crenilabis) caught at Al-Duqum and Salalah in the Arabian Sea region of Oman were sampled monthly between January 2001 and December 2002. The total length (TL) of mullet caught with gill- and seine nets ranged from 12 to $54.5 \mathrm{~cm}(32.4 \mathrm{~cm}$ mean $\pm \mathrm{SD} ; \mathrm{n}=2445)$ but $<2 \%$ of specimens had a $\mathrm{TL}<24 \mathrm{~cm}$, suggesting gear selectivity. Females dominated samples $(1: 0.36)$ and reached $\mathrm{L}_{50}$ at $32.8 \mathrm{~cm} \mathrm{TL} \mathrm{(32.2} \mathrm{cm}$ in males). Length weight relationships were non-linear and conversion factors between TL, fork length (FL) and standard length (SL) were calculated. Proportionately, most females had ripe gonads in September and October, and males in September to November. Both female and male gonadosomatic indices (GSI) peaked in September and October and were lowest between May and August. The peak in reproductive activity coincides with the fall intermonsoon, when the Arabian Sea upwellings caused by the onshore winds of the SW monsoon season (June to August/September) retreat. During this intermonsoon period the inshore water temperatures begin to rise after reaching a minimum in August/September. Some reproductive activity also occurs in other months, particularly February, when water temperatures are seasonally lower.

Keywords: Crenimugil crenilabis, reproductive season, length-weight relationships, Oman.

$\overline{\text { *Corresponding author. E-mail: alnahdi22@hotmail.com }}$ 


\section{Introduction}

The fringelip mullet Crenimugil crenilabis (Forsskål, 1775) is a coastal species from the tropical waters of the Indo-Pacific, mainly between $32^{\circ} \mathrm{S}$ and $32^{\circ} \mathrm{N}$, and shallower than $20 \mathrm{~m}$ depth (Fischer and Bianchi, 1984). Single individuals or small schools occur over coral reefs and reef flats, and in lagoons with sandy or muddy substrata and harbours, and juveniles are sometimes found in tide-pools (Al-Abdessalaam, 1995; Randall, 1995).

Crenimugil crenilabis is one of at least 11 mullet species known from the coastal waters of Oman (Al-Abdessalaam, 1995), where they are caught by fishers using non-selective gill- and seine nets, often from small fiberglass boats with outboard engines. Government statistics show that the annual catches of mullets have increased from 123t in 2000 to $839 t$ in 2005, however detailed catch-by-species statistics are unavailable for the Mugilidae (Anon, 2006). Nevertheless, C. crenilabis is common in fish markets and in biological samples collected by fisheries observers at landing sites, and it therefore makes up a substantial proportion of mullet catches. Of the total mullet catch from Oman in 2005, 58\% came from the Gulf of Oman and the rest from the Arabian Sea (Anon, 2006); the latter fishery is seasonal, declining sharply over the SW monsoon period (May-August).

Very little information is available on the general biology of $C$. crenilabis in the primary literature. It attains a maximum size of $50-55 \mathrm{~cm}$ (Al-Abdessalaam, 1995; Randall, 1995), and feeds on detritus containing algae and microscopic animals by scooping up the upper sand or mud layers and filtering through the gills . Reproduction is oviparous and eggs are pelagic and non-adhesive (Breder, and Rosen, 1966). Helfrich and Allen (1975) observed spawning in large aggregations near the surface at night, at the beginning of an ebb tide in June. This observation was made over shallow open areas of a lagoon slope at Enewetok atoll in the Marshall Islands. Apart from the above, the basic biological parameters that are fundamental to the management of exploited fish populations are unknown for $C$. crenilabis in Oman. The aims of this study were to determine the length-weight relationships, conversion factors among various length measurements, size composition of captured fish, size at reaching sexual maturity and reproductive season of C. crenilabis from the Arabian Sea coast of Oman.

\section{Material and Methods}

Catches made by traditional fishers at Al-Duqum and Salalah (Fig. 1) were sampled by Marine Science and Fisheries Center (MSFC) staff between January 2001 and December 2002. Random samples from Al-Duqum were measured to determine lengthweight relationships and conversion factors. Length measurements were made to the nearest $0.1 \mathrm{~cm}$ of total length and all mean values were reported \pm SD. (TL; from the anterior tip of the snout to the posterior tip of the caudal fin, with the caudal fin lying straight and not in its natural position), standard length (SL; anterior tip of the snout to the anterior base of the caudal fin rays) and fork length (FL; anterior tip of the snout to the anterior margin of the fork in the caudal fin), and total weight was determined to the nearest 1 $\mathrm{g}$ on an electronic balance. Non-linear length weight regressions $\left(\mathrm{TW}=\mathrm{aTL}^{\mathrm{b}}\right.$ ) were calculated for males, females and both sexes combined using a least squares fit, and regressions were compared using ANCOVA test (Zar, 1984). Linear regressions of TL versus SL and TL versus FL were calculated to determine conversion factors.

Monthly subsamples (approximately 40 specimens, randomly selected) were collected at AlDuqum, and the gonads removed, sexed and weighed to the nearest $0.01 \mathrm{~g}$. These gonads were classified into six macroscopically distinguishable stages for females and four stages for males (Table 1).

To calculate the size at which $50 \%$ of females reach sexual maturity $\left(\mathrm{L}_{50}\right)$, the proportions of females with ovaries in stages $2-5$ per $2-\mathrm{cm}$ size class were fitted to a logistic equation of the form:

$$
\mathrm{P}=1(1+\exp (\mathrm{a}-\mathrm{bTL})
$$

where $\mathrm{P}$ is the proportion of mature females in each length class, TL is total length, and a and $\mathrm{b}$ are constants. The best fit model was obtained by minimizing the sum of squares, and the length at $50 \%$ maturity was determined by back-calculation. The same method was used to calculate the male $\mathrm{L}_{50}$, using the grouped stages 2-4 as the mature proportion in each length class.

A gonadosomatic index (GSI; mean $\pm \mathrm{SD}$ ) was calculated for females and males respectively for each month as follows: GSI $=\mathrm{GW} / \mathrm{TW} \times 100$. The liver of each fish was weighed ( $\mathrm{LW} \pm 0.01 \mathrm{~g}$ ) and the hepato- 


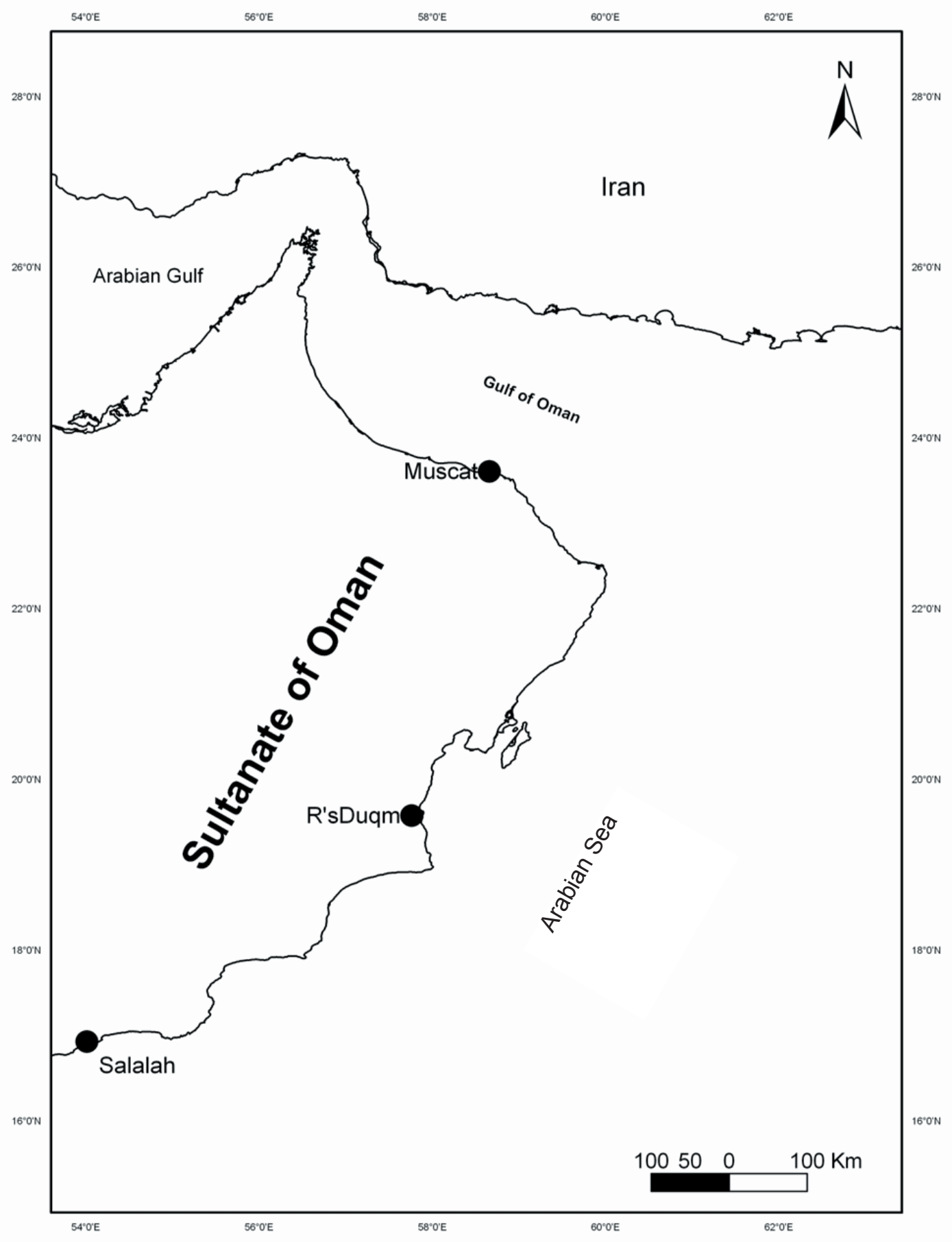

Figure 1. The sampling sites along the Arabian Sea coastline. 
Table 1. Macroscopically distinguishable stages of female and male gonads.

\begin{tabular}{lll}
\hline Sex & Stage & Characteristics \\
\hline \multirow{2}{*}{ Female } & 0 & Immature or resting - thin, short, transparent and no eggs visible \\
& 1 & $\begin{array}{l}\text { Developing - cream/yellow, longer in appearance, eggs not visible } \\
\text { Maturing - developed, yellow to opaque eggs visible to naked eye }\end{array}$ \\
& 2 & Ripe and spawning - well-developed and swollen, hydrated oocytes \\
& 4 & Spent- Translucent, pale violet with obvious blood vessels \\
Male & 5 & Post-spent - Empty, shrunk, violet, flaccid \\
& 1 & Developing - small, occupying about $1 / 3$ of body cavity, transparent/pale \\
& 2 & Maturing - whitish/translucent, occupying about $1 / 2$ of body cavity \\
& 3 & Ripe - creamy white, occupying about $3 / 4$ of body cavity \\
& 4 & Spent/atrophied - flabby, reddish, about $1 / 2$ of body cavity \\
\hline
\end{tabular}

somatic index (HSI; mean $\pm \mathrm{SD})$ calculated as HSI $=$ $\mathrm{LW} / \mathrm{TW} \times 100$ for each month.

\section{Results and Discussion}

The largest female was $51.4 \mathrm{~cm}$ TL and weighed 1611 $\mathrm{g}$, and the largest male was $54.5 \mathrm{~cm}$, and weighed $1684 \mathrm{~g}$. These measurements are consistent with the maximum size of $51-55 \mathrm{~cm}$ TL provided by Randall (1995) and Al-Abdussalaam (1995). The TL of all fish measured ranged from $12 \mathrm{~cm}$ to $54.5 \mathrm{~cm}$ with a mean size of $32.4 \pm 4.4 \mathrm{~cm}($ S.D $) \quad(\mathrm{n}=2445)$. Less than $2 \%$ of samples comprised fish $<24 \mathrm{~cm}$ TL, suggesting that the gear used to catch mullets select fishes above that size (Fig. 1). There was no significant difference in size between females $(37.3 \pm 7.0 \mathrm{~cm}, \mathrm{n}=329)$ and males $(36.7 \pm 6.4 \mathrm{~cm}, \mathrm{n}=117 ; \mathrm{t}=0.79, \mathrm{df}=444, \mathrm{p}>0.05)$ in the samples taken at Al-Duqum, and in these samples females dominated at a ratio of 1 female to 0.36 males $\left(\chi^{2}=100.77, \mathrm{p}<0.001\right)$. During April, June, July and December, no male individuals could be collected.

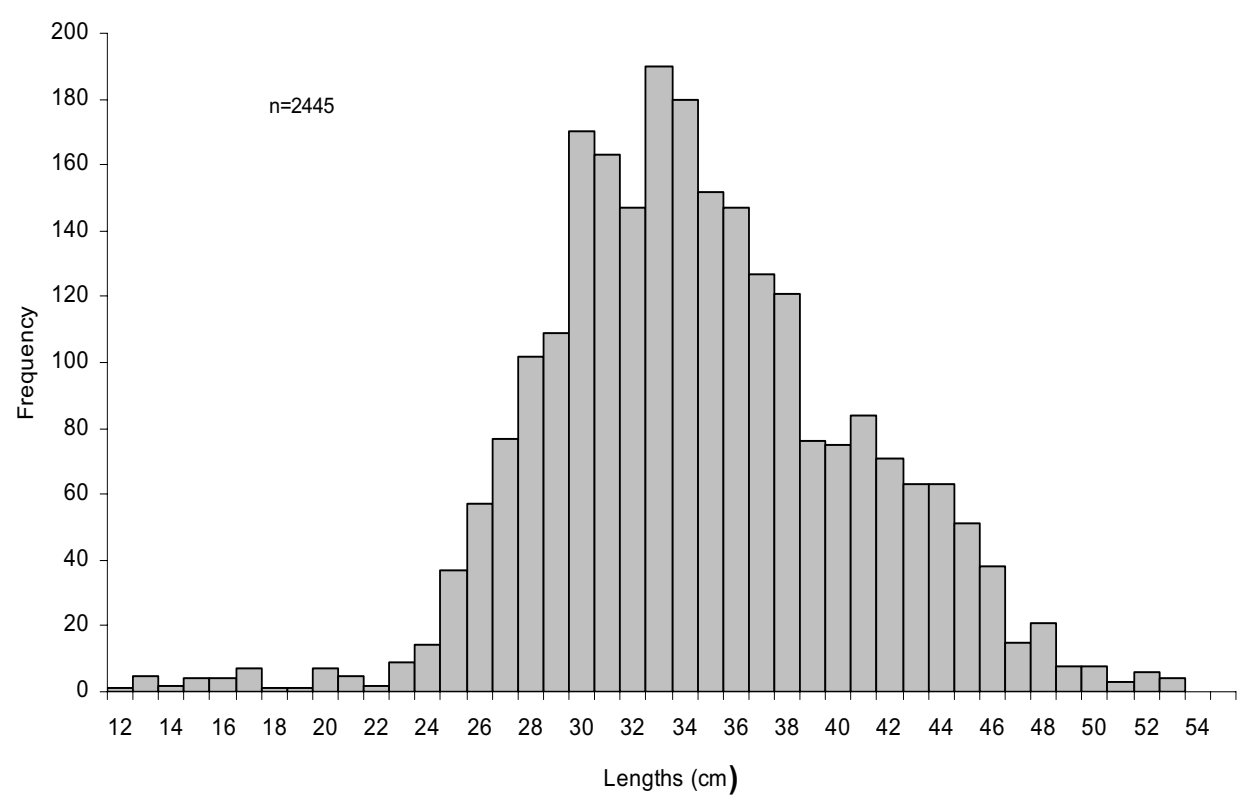

Figure 2. Length composition (TL in $\mathrm{cm}$ ) of $C$. crenilabis caught by artisanal fishers using gill and seine nets at Al-Duqum and Salalah during 2001. 
Table 2. Linear regressions of TL versus SL and FL for C. crenilabis females $(\mathrm{n}=329 ; 14-52 \mathrm{~cm} \mathrm{TL})$, males $(\mathrm{n}=117 ; 25-54 \mathrm{~cm} \mathrm{TL})$ and sexes combined, and conversion factors among length measurements.

\begin{tabular}{lcc}
\hline Sex & Equation & $\mathrm{R}^{2}$ \\
\hline F & SL $=0.772 \mathrm{TL}+0.2284$ & 0.964 \\
M & SL $=0.780 \mathrm{TL}-0.0619$ & 0.971 \\
All & $\mathrm{SL}=0.774 \mathrm{TL}+0.1732$ & 0.966 \\
F & $\mathrm{FL}=0.870 \mathrm{TL}+0.8806$ & 0.984 \\
M & $\mathrm{FL}=0.864 \mathrm{TL}+1.0546$ & 0.982 \\
All & $\mathrm{FL}=0.869 \mathrm{TL}+0.9093$ & 0.984 \\
\hline
\end{tabular}

This indicates that there may be segregation among sexes. However, this has to be verified by subsequent studies.

The length-weight relationships were $\mathrm{TW}_{\text {females }}$ $=0.0222 \times \mathrm{TL}^{2.801}\left(\mathrm{n}=329, \mathrm{r}^{2}=0.9499\right), \mathrm{TW}_{\text {males }}$
$=0.0126 \times \mathrm{TL}^{2.9441}\left(\mathrm{n}=117, \mathrm{r}^{2}=0.9473\right)$, and $\mathrm{TW}_{\text {both }}$ $=0.0247 \times \mathrm{TL}^{2.7693}\left(\mathrm{n}=446, \mathrm{r}^{2}=0.9426\right)($ Fig. 2). The log-transformed data fitted best to linear models $\left(\log \mathrm{TW}_{\text {males }}=2.9441 \times \log \mathrm{TL}-1.9004\right.$ and $\log \mathrm{TW}_{\text {females }}$ $=2.801 \times \log \mathrm{TL}-1.6541)$ and the regression slopes differed significantly between sexes (ANCOVA, $\mathrm{F}=$ $1.31, \mathrm{p}>0.05$ ), females being slightly heavier than males of the same TL, except at the largest sizes. The linear regressions of TL versus FL and SL respectively fitted the data with $r^{2}$-values $>0.96$ in all cases, and the equations and conversion factors are shown in Table 2.

The logistic models fitted to the mature proportions of females $(n=337)$ and males $(n=117)$ resulted in minimized sums of squares of 0.18 and 0.042 , respectively (Fig. 3). The smallest female with a developing ovary (stage 1) had a TL of 25.5 $\mathrm{cm}$, and $50 \%$ of females reached sexual maturity at
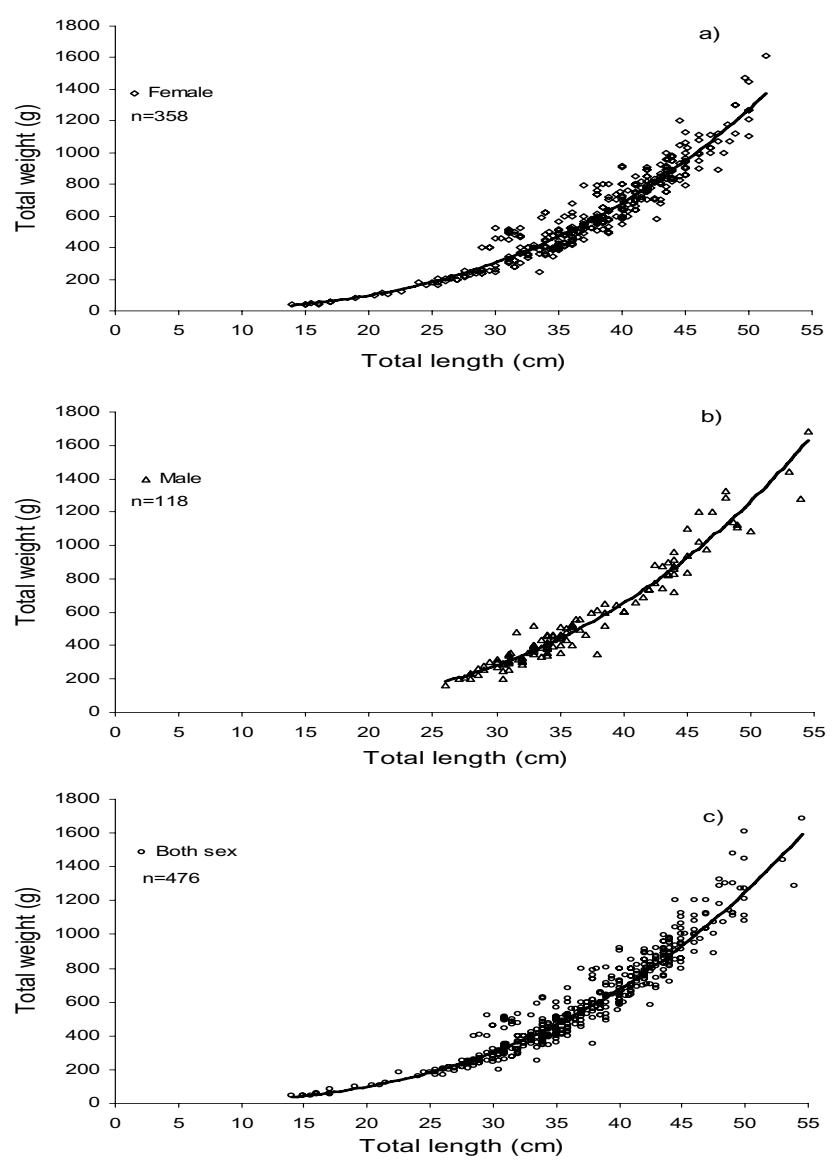

Figure 3. Total length and total weight relationships of C. crenilabis females (a), males (b) and both sexes combined (c). 


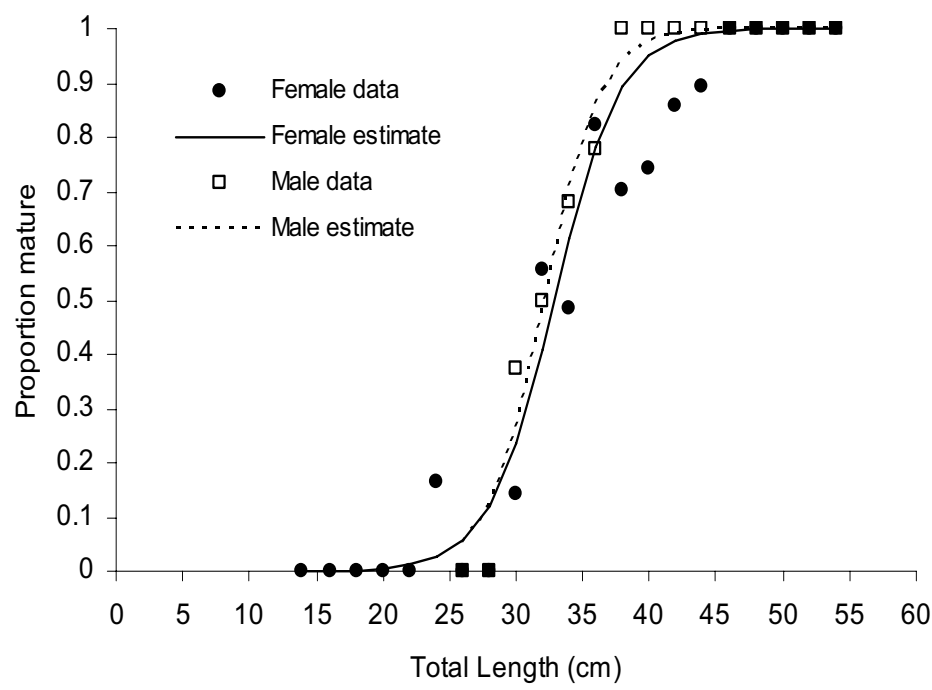

Figure 4. The proportions of mature C. crenilabis per 2-cm TL interval and logistic curves fitted to estimate $\mathrm{L}_{50}$ values for females and males.

$32.8 \mathrm{~cm}$. The smallest male with a maturing gonad had a TL of $30 \mathrm{~cm}$, and males reached $\mathrm{L}_{50}$ at 32.2 $\mathrm{cm}$. Males and females therefore reach maturity at similar sizes, comparable to that of Mugil cephalus (Linnaeus, 1758). Male M. cephalus in South Carolina first became mature at $24.8 \mathrm{~cm}$ TL $(100 \%$ are mature at $30 \mathrm{~cm}$ ) and females first matured at 2 years and $29 \mathrm{~cm}$ TL $(100 \%$ were mature after 4 years at 40 $\mathrm{cm}$ ) (McDonough and Wenner, 2000), and similar estimates were obtained from the Gulf of Mexico (28 $\mathrm{cm}$ and $29.9 \mathrm{~cm}$ TL respectively; Ibañez-Aguirre and Gallardo-Cabello, 1996). These values are close to our estimates for C. crenilabis.

The weights of ovaries ranged from $0.21 \mathrm{~g}$ (at a $\mathrm{TW}=264 \mathrm{~g})$ to $73.12 \mathrm{~g}(\mathrm{TW}=947 \mathrm{~g})$ and that of male gonads from $0.14 \mathrm{~g}(\mathrm{TW}=321 \mathrm{~g})$ to $49 \mathrm{~g}(\mathrm{TW}=1200$ g). Of 349 ovaries sampled, $47.8 \%$ were immature and developing (stages 0 and 1), and these early stages were more prevalent in January to June (Fig. 5a). Active ovaries (stages 2-4, comprising $39.5 \%$ of all ovaries) were present in all months, with the highest proportions occurring in September and October, and moderately high proportions in November, December and February. Post-spent ovaries (stage 5) decreased gradually between July and November
(Fig. 5a). These trends suggest a peak spawning season in September to October (highest ripe and lowest developing proportions), although spawning clearly continues at a lower level into November and December. The February peak may be an extension of the main spawning season, or a secondary spawning event as reported in M.cephalus from Hong Kong (Bromhall, 1954) and Gulf of Mexico (Stenger, 1959). Nevertheless, it is clear that female reproductive activity is depressed between May and August.

Of 117 male gonads sampled, $32.2 \%$ were developing (stage 1), $44.8 \%$ were maturing or ripe (stages 2-3) and 23\% were spent or atrophied (stage 4). Ripe male gonads were present in all months. Data from months with sample sizes $<5$ were excluded, and the remaining data suggest an increased ripe proportion in September to November, compared to January to March and May (Fig. 5b). Furthermore, the monthly proportions of males with developing gonads decreased gradually from August to November; these males presumably becoming ripe with the approach and onset of peak spawning. Therefore, the trends in male gonad development and ripening tend to support the theory of peak spawning in September to November, with some activity in January to March. 
a) Females

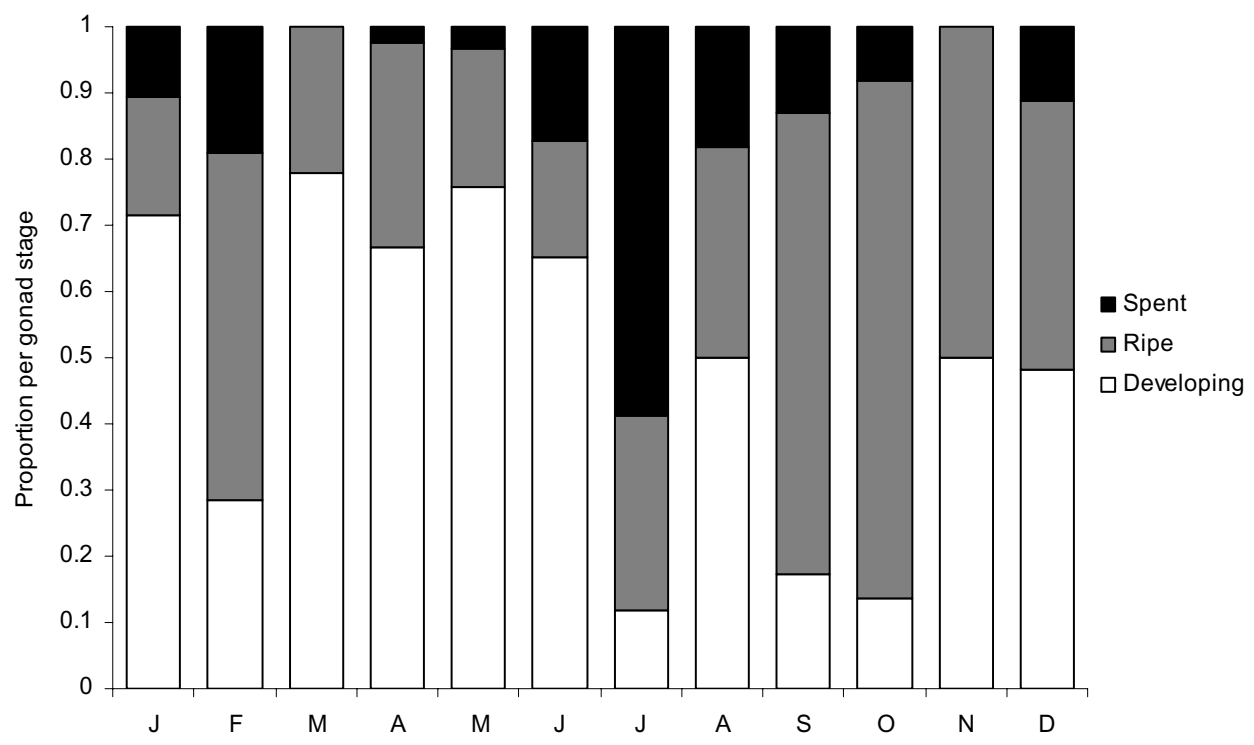

b) Males

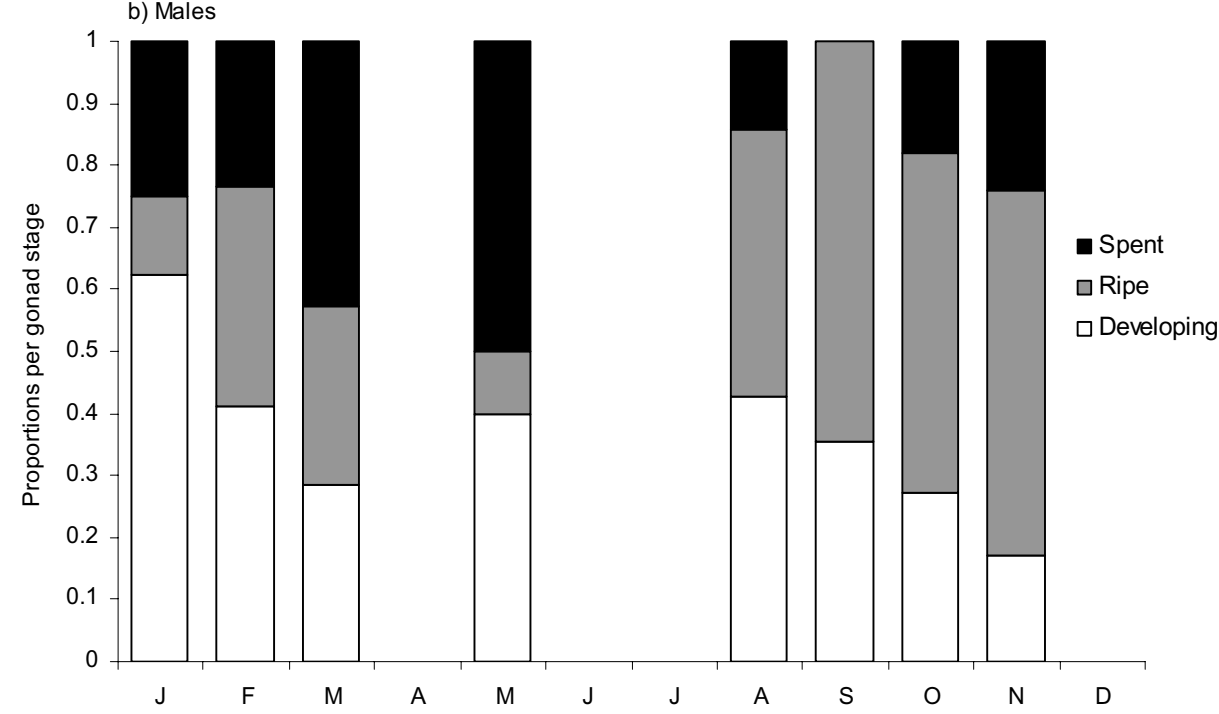

Figure 5. Monthly proportions of (a) female C. crenilabis gonads classified as developing (stages 0 and 1), maturing, ripe and spent (stages 2-4) and post-spent (stage 5), and (b) male gonads classified as developing (stage 1), maturing and ripe (stages 2 and 3) and spent (stage 4). Sample sizes were 349 females and 117 males, and monthly samples with $<5$ datapoints were removed. 

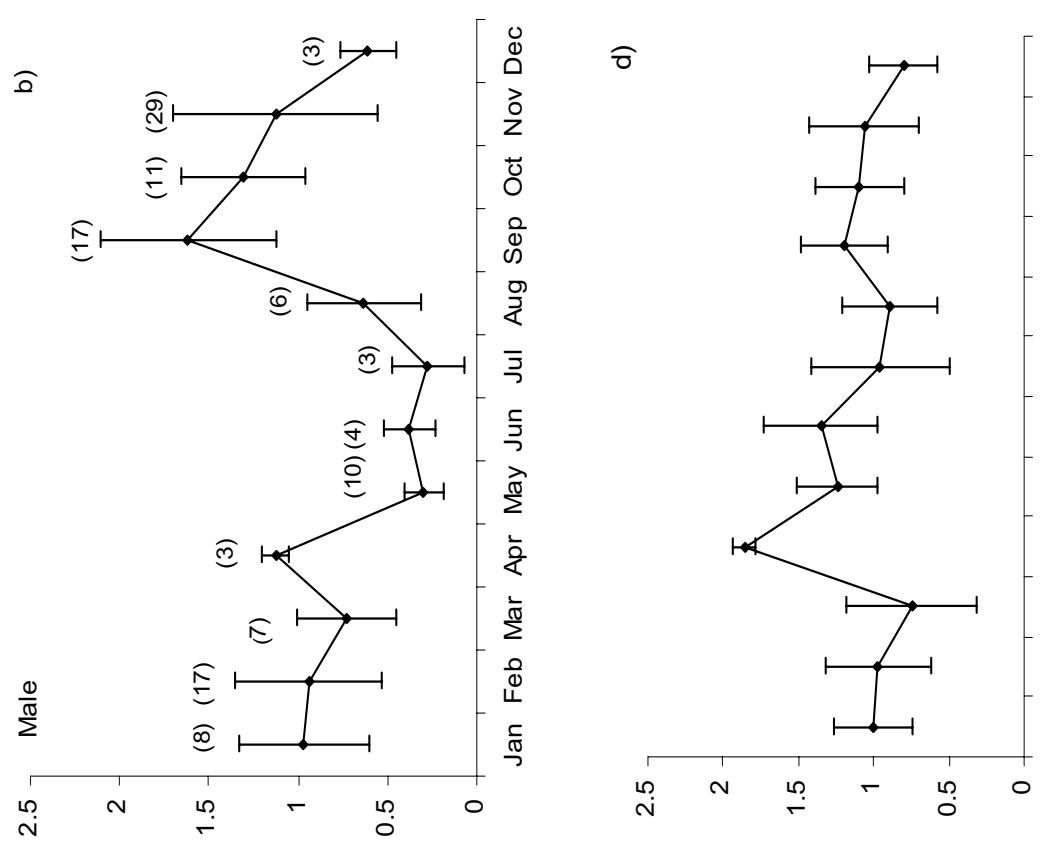

흄

곻

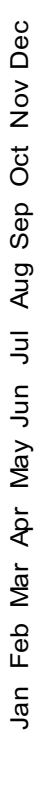

ฮं

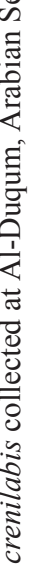

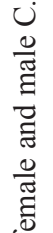
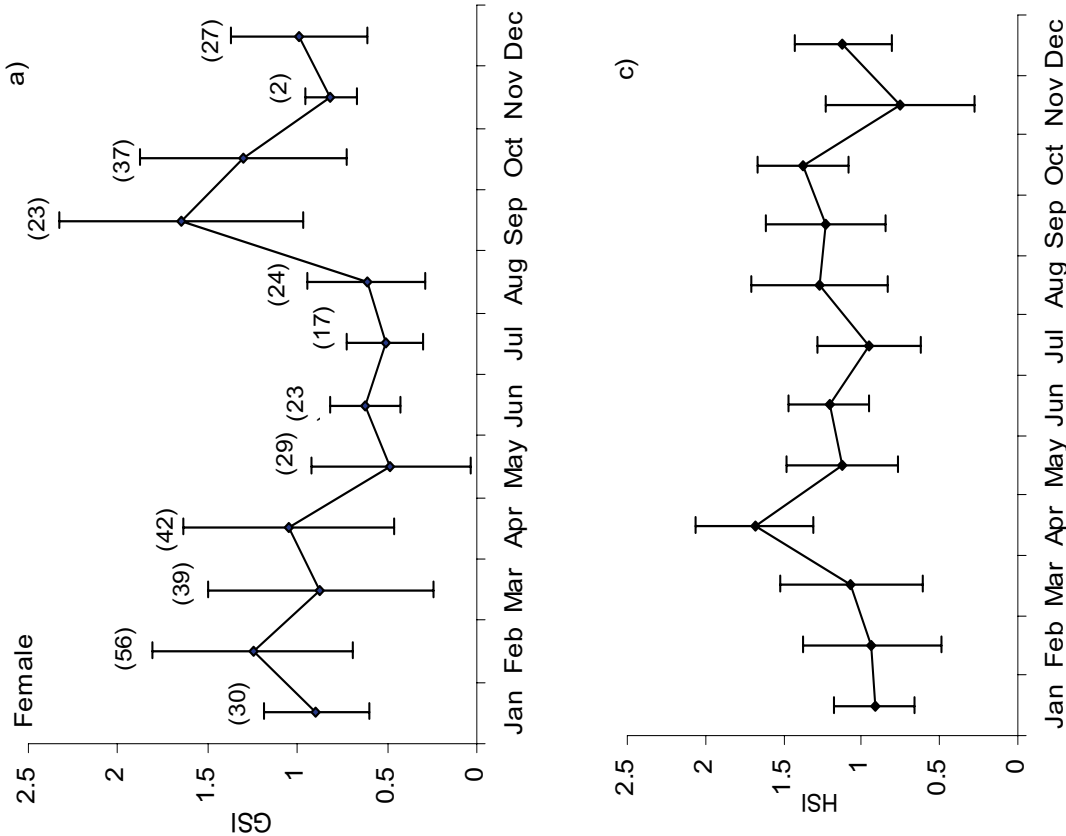

0
0
0
0
.0
0
0
0
0
0

.

हี क

के

䒕

홀

त

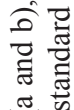

. 믈

हี 
Both female and male GSI trends (Fig. 6a and b) peak in September and October and were lowest between May and August. Apart from the male values for December, the GSI values remain moderately high from November to April. This suggests that the peak spawning in September to October was followed by a period of spawning activity at a lower level, that was interrupted by the SW monsoon season (May to August) in the Arabian Sea. Livers weighed between $0.4 \mathrm{~g}$ and $40.2 \mathrm{~g}$, and the HSI trends of males and females peaked in April, just prior to the SW monsoon season (Fig. 6c and d). A sharp decline in the HSI of females between October and November (Fig. 6c) presumably reflects the metabolic energy expenditure and depletion of liver resources during spawning (Busacker et al,, 1990).

Earlier studies on the relationships between spawning in mullets and environmental variables (mainly temperature and photoperiod) showed a tenuous linkage at best (see review by Nash and Shehadeh, 1980). Their summary of an extensive and conflicting dataset including seven species over a wide geographical range failed to define a clear pattern, and they concluded that spawning areas of certain species of mullets were those places where optimum conditions for the incubation of eggs and the young were available. These conditions differed from region to region, influencing indigenous mullet populations.

The present study suggests that peak spawning in $C$. crenilabis during the fall intermonsoon in the Arabian Sea (September and October), and Thangaraja (1995) showed lowest annual but increasing temperatures (generally from $<25^{\circ} \mathrm{C}$ to $>26^{\circ}$ ) in inshore waters at several sites in August and September. The gradual warming after August and September follows on the retreat of cooler upwelled waters that are a prominent feature of this coast during the SW monsoon period (May to August/September) (Kindle and Arnone, 2001). We therefore tentatively suggest that low water temperatures and a gradual increase may initiate spawning in C. crenilabis in the Arabian Sea, but that spawning (possibly at a lower level) continues into the warming NW monsoon months. Such a pattern was also shown for Mugil curema along the Atlantic coast of the United States, where spawning began in early spring when temperatures were rising (Anderson, 1957 cited in Nash and Sehadeh, 1980). Conversely, M. cephalus spawned when water temperatures were falling during late fall or winter (Nash and Sehadeh, 1980).

Thangaraja (1995) reported low February water temperatures $\left(20-25^{\circ} \mathrm{C}\right)$ at 3 sites along the Dhofar coast (Salalah, Taqah and Raysut). If lower (and rising) temperatures do in fact initiate spawning in C. crenilabis (see above), these lower February temperatures may explain the larger proportion of females with ripe gonads seen in that month in Fig. 6a. It should be noted that the spawning season of $C$. crenilabis in the Arabian Sea region of Oman may differ from the Gulf of Oman, where the temperature is not as strongly affected by the SW monsoon winds and upwellings. Lowest water temperatures at Muscat (Gulf of Oman) are generally recorded during February and March (late winter; Thangaraja, 1995), and based on our results in the present study we hypothesize that spawning of C. crenilabis in the Gulf of Oman will take place in February to March, as opposed to mainly September and October in the Arabian Sea.

\section{Acknowledgements}

We are grateful to Dr. H. Al-Oufi, Under-Secretary of the Ministry of Fisheries Health, and Dr. A.H. AlHosni, Director General for Fisheries Research and Extension, Government of Sultanate of Oman for their keen interest and encouragement in the preparation of this paper. We thank Drs. J. Groeneveld, N. Jayabalan and B. Human for their support in preparing the manuscript. Many of the staff of the Marine Science and Fisheries Centre assisted with data collection at sea or at landing sites, and in the laboratory. Funding was by the Development of Agriculture and Fisheries Fund.

\section{References}

Al-Abdessalaam, T.Z.S. 1995. Marine Species of the Sultanate of Oman: An Identification Guide. Ministry of Agriculture and Fisheries, Marine Science and Fisheries Centre, Sultanate of Oman. Muscat Printing Press, 412 pp.

Anon. 2006. Fisheries Statistics Book (2005) for the Sultanate of Oman. Directorate of General Planning and Investment Promotion. Statistics and Information Department, Ministry of Agriculture and Fisheries, Muscat, $240 \mathrm{pp}$.

Bromhall, J.D. 1954. A note on the reproduction of the grey mullet (Mugil cephalus Linnaeus), Hong Kong Univ. Fish Journal, 1:19-34. 
Busacker, G.P., I.R. Adelman and E.M. Goolish. 1990. Growth. In: Methods for Fish Biology, B. Schreck and P.B. Moyle, (Editors), 363-387. American Fisheries Society, Bethesda, Maryland.

Fischer, W. and G. Bianchi. 1984. FAO Species Identification Sheets for Fishery Purposes. Western Indian Ocean (Fishing Area 51). Prepared and printed with the support of the Danish International Development Agency (DANIDA). Rome, Food and Agricultural Organization of the United Nations, vols. 1-6:pag.var.

Helfrich, P. and P.M. Allen. 1975. Observations on the spawning of mullet, Crenimugil crenilabis (Forskal), at Enewetak, Marshall Islands. Micronesia, 11:219-225.

Ibañez-Aguirre, A.L. and M. Gallardo-Cabello. 1996. Age determination of the grey mullet Mugil cephalus L. and the white mullet M. curema. V. (Pisces: Mugilidae) in Tamiahua lagoon, Veracruz. Ciencia Marina 22:329-345.

Kindle, J.C. and R.A. Arnone. 2001. A review of the surface circulation of the Northern Arabian Sea. In: Proceedings of the $1^{\text {st }}$ International Conference on Fisheries, Aquaculture and Environment in the NW Indian Ocean, M. Claereboudt, S. Goddard, H. Al-
Oufi, and J. McIlwain (Editors), 113-122. Sultan Qaboos University, Muscat, Sultanate of Oman.

McDonough, C.J. and C.A. Wenner. 2000. Growth, recruitment, and abundance of juvenile striped mullet (Mugil cephalus) in South Carolina estuaries. Fishery Bulletin, 101:343-357.

Nash, C.E. and Z.H. Shehadeh. 1980. Review of breeding and propagation techniques for grey mullet, Mugil cephalus L. ICLARM Studies and Reviews 3, 87pp. International Center for Living Aquatic Resources Management, Manila, Philippines.

Randall, J.E. 1995. Coastal Fishes of Oman. Crawford House Publishing Pty Ltd, Bathurst, New South Wales, Australia. 439pp.

Stenger, A.H. 1959. A study of the structure and development of certain reproducrive tissues of Mugil cephalus Linnaeus. Zoologica, N.Y., 44: 53-68.

Thangaraja, M., 1995. Hydrobiology off Oman. MSFC Research Report 95-1. Marine Science and Fisheries Centre, Muscat, Oman. 153 pp.

Zar, J.H. 1984. Biostatistical Analysis. Englewood Cliffs, Prentice-Hall, New Jersey, xiv $+718 p$. 